\title{
Características morfogênicas, estruturais e produtivas de acessos de capim-buffel ${ }^{1}$
}

\section{Morphogenetical, structural and access to productive buffel grass}

\author{
José Armando de Sousa Moreira ${ }^{2}$; Jailson Lara Fagundes ${ }^{3 *}$; Claudio Mistura ${ }^{4}$; \\ Nailson Lima Santos Lemos ${ }^{5}$; José Nilton Moreira ${ }^{6}$; Alfredo Acosta Backes ${ }^{3}$; \\ Juciléia Aparecida da Silva Morais ${ }^{3}$; Veronaldo Souza de Oliveira3; \\ Andréia Luciane Moreira ${ }^{7}$
}

\section{Resumo}

Embora o capim-buffel seja tão importante para os sistemas produtivos no semiárido brasileiro, estudos com essa forrageira são ainda escassos e pouco difundidos, dessa forma conduziu-se este experimento com o objetivo de avaliar as características morfogênicas, estruturais e produtivas de seis acessos de capim-buffel (Cenchrus ciliaris L.) pertencentes ao banco ativo de germoplasma (BAG) da Embrapa semiárido. O experimento foi realizado no Departamento de Tecnologia e Ciências Sociais (DTCS) da Universidade do Estado da Bahia (UNEB), no período de novembro de 2008 a janeiro de 2009. O delineamento experimental utilizado foi inteiramente casualizado com seis acessos de capim-buffel (Tanzânia, Pusa Giant, Áridus, Buchuma, Irã e Biloela) e cinco repetições, totalizando 30 unidades experimentais. Com relação aos resultados, os acessos diferiram estatisticamente na maior parte das variáveis analisadas, principalmente nas variáveis morfogênicas e estruturais. Observou-se que o capim-buffel apresenta uma taxa de aparecimento média de uma folha a cada quatro dias em cada perfilho, com um tempo de vida da folha de 17 dias, mantendo dez folhas vivas por perfilho. Apesar de serem constatadas diferenças morfogênicas e estruturais entre os acessos de capim-buffel as mesmas não influenciaram nos parâmetros produtivos.

Palavras-chave: Cenchrus ciliares, fibra em detergente neutro, relação folha/colmo, massa seca de lâmina foliar, taxa de alongamento de colmo

\footnotetext{
Abstract

Although the buffel grass is so important to the productive systems in the semiarid Brazilian studies with this forage are still scarce and diffused, so this experiment was conducted to evaluate the morphogenesis, structural and productive six accessions of buffel grass (Cenchrus ciliaris L.) belonging to the active germplasm bank (BAG) Embrapa semiarid. The experiment was conducted at the Department of Technology and Social Sciences (DTCS) University of Bahia (UNEB), from December 2008 to

${ }^{1}$ Parte da tese de Doutorado do Programa de Pós-Graduação em Zootecnia da Universidade Federal de Sergipe.

2 Discente do Curso de Mestrado do Programa de Pós-Graduação em Zootecnia, Universidade Federal de Sergipe, UFS, São Cristóvão, SE. E-mail: ze_armando@hotmail.com

${ }^{3}$ Profs., Dept ${ }^{\circ}$ de Zootecnia, UFS, São Cristóvão, SE. E-mail: ratinhojlf@yahoo.com.br; alfredoaab_67@yahoo.com.br; jucileia@ yahoo.com.br; veronaldo@yahoo.com.br

${ }^{4}$ Prof., Dept $^{\circ}$ de Tecnologia e Ciências Sociais, Universidade do Estado da Bahia, UESB, Juazeiro, BA. E-mail: cmistura@ig.com.br

${ }^{5}$ Prof., Dept ${ }^{\mathrm{o}}$ de Agronomia da Faculdade Nordeste da Bahia, FANEB, Coronel João Sá, BA. E-mail: agronailson@yahoo.com.br

${ }^{6}$ Pesquisador da Embrapa Semiárido, Petrolina, PE. E-mail: jose.moreira@embrapa.br

7 Pesquisadora do Polo Alta Sorocabana, APTA/SAA, Presidente Prudente, SP. E-mail: aluciane@apta.sp.gov.br

* Autor para correspondência
} 
January 2009. The experimental design was completely randomized with six accessions of buffel grass (Tanzania, Pusa Giant, Aridus, Buchuma, Iran and Biloela) and five replicates, totaling 30 experimental units. Regarding the results, the accessions differed significantly in most variables, especially in morphogenetic and structural variables. It was observed that the buffel grass provides a mean rate of appearance of one sheet every four days in each tiller, with a lifetime of sheet 17 days, keeping ten per tiller. Although they found morphogenetic and structural differences between accessions of buffel grass they did not affect the production parameters.

Key words: Cenchrus ciliares, neutral detergent fiber, leaf/stem ratio, dry mass leaf lamina, stem elongation rate

\section{Introdução}

Os sistemas de produção de ruminantes no semiárido caracterizam-se pelo predomínio de sistemas extensivos, os quais têm a Caatinga como fonte principal de volumoso. Entretanto a produção das pastagens nativas da Caatinga é limitada devido a marcante sazonalidade, o que torna o sistema produtivo vulnerável ao longo do ano.

Nos últimos anos, têm-se observado uma evolução significativa na atividade pecuária no semiárido, principalmente, em relação à disponibilidade de forragem através de técnicas de manipulação da Caatinga. Dentre as técnicas, o enriquecimento da Caatinga tem se destacado, pois consiste na introdução de forrageiras adaptadas a tais condições climáticas com vistas na melhoria da quantidade e qualidade de forrageiras ofertadas aos animais.

De acordo com Moreira et al. (2007), dentre as gramíneas introduzidas, merecem destaque as dos gêneros Brachiaria, Andropogon, e principalmente as do gênero Cenchrus, a exemplo do capim-buffel que atualmente exerce um papel fundamental na atividade pecuária nordestina.

O capim-buffel é a gramínea que, atualmente, apresenta-se com maior destaque das pastagens cultivadas no semiárido nordestino. Originário da África, Índia e Indonésia, foi introduzida no Brasil na década de 50. É uma espécie perene, de porte variando de 0,6 a 1,5 m de altura, dependendo da cultivar.
Segundo Moreira et al. (2007), o capim-buffel é uma gramínea que apresenta alta resistência ao déficit hídrico, apresentando um sistema radicular profundo que lhe permite ter acesso à água de forma rápida e por mais tempo, além da acumulação de reservas nutritivas na base das suas hastes para uma possível liberação lenta quando necessário. Segundo Rangel et al. (2009), a incorporação desta gramínea aos sistemas produtivos, não têm sido proporcional a geração de tecnologias referente à mesma, sendo ainda a tecnologia pouco difundida.

A EMBRAPA Semiárido mantém em seus campos experimentais uma coleção de 114 acessos de capim-buffel, para tanto, a caracterização e avaliação de cultivares é necessária a fim detectar características desejáveis que forneça subsídios para outras pesquisas visando o uso eficiente desta forrageira como suplemento a Caatinga.

De acordo com Silva e Nascimento Junior (2007), a análise morfofisiológica para uma planta forrageira é uma importante ferramenta para a determinação das condições do pasto. Cecato et al. (2007), comenta que o conhecimento das variáveis morfogênicas e estruturais, assim como a utilização desse conhecimento no manejo do pasto, pode otimizar a utilização no sistema, sem elevar os custos de produção.

Neste sentido, objetivou-se avaliar as características morfogênicas, estruturais e produtivas de diferentes acessos de capim-buffel, pertencentes ao banco ativo de germoplasma (BAG) da EMBRAPA Semiárido. 


\section{Material e Métodos}

O experimento foi realizado no Departamento de Tecnologia e Ciências Sociais (DTCS) da Universidade do Estado da Bahia (UNEB), em casa de vegetação, no período de novembro de 2008 a janeiro de 2009, perfazendo 70 dias de avaliação.

$\mathrm{O}$ delineamento experimental utilizado foi inteiramente casualizado sendo seis acessos de capim-buffel (Tanzânia, Pusa Giant, Aridus, Buchuma, Irã e Biloela) com cinco repetições, totalizando 30 unidades experimentais.

As unidades experimentais foram constituídas de vasos. Cada vaso foi composto de $11 \mathrm{~kg}$ de solo classificado como Neossolo Flúvico Psamíticos (EMBRAPA, 2006).

Segundo a análise química o solo apresentou as seguintes características: $\mathrm{MO}=9,05 \mathrm{~g} / \mathrm{kg} ; \mathrm{pH}$ em $\mathrm{H}_{2} \mathrm{O}=5,5 ; \mathrm{P}=7 \mathrm{~g} / \mathrm{dm}^{3} ; \mathrm{S}: 2,92 \mathrm{cmolc} / \mathrm{dm}^{3} ; \mathrm{K}=0,2$ $\mathrm{cmolc} / \mathrm{dm}^{3} ; \mathrm{Ca}=1,86 \mathrm{cmolc} / \mathrm{dm}^{3} ; \mathrm{Mg}=0,89 \mathrm{cmolc} /$ $\mathrm{dm}^{3} ; \mathrm{Al}=0,05 \mathrm{cmolc} / \mathrm{dm}^{3} ; \mathrm{H}=1,15 \mathrm{cmolc} / \mathrm{dm}^{3} ; \mathrm{V}$ $=70 \%$.

Durante o período experimental foi feita adubação com aplicação de $50 \mathrm{~kg}$ de $\mathrm{P}_{2} \mathrm{O}_{5} /$ ha na forma de superfosfato triplo e de $100 \mathrm{~kg}$ de $\mathrm{N} / \mathrm{ha}$ na forma de ureia, fracionados em duas aplicações, sendo metade no plantio e a outra metade 15 dias após o estabelecimento das mudas. Os vasos foram irrigados diariamente com o intuito de manter o solo com nível de umidade próximo à capacidade de campo.

Os acessos foram semeados em bandejas de isopor e, posteriormente, foram selecionadas três plantas dos acessos em estudo para cada vaso experimental, onde, após o estabelecimento, procederam-se as avaliações pertinentes ao protocolo experimental.

Para a determinação das variáveis morfogênicas e estruturais foi utilizada a técnica dos perfilhos marcados. Utilizou-se sete perfilhos por vaso os quais, a cada três dias, foram avaliados os seguintes parâmetros: comprimento das folhas emergentes e expandidas; comprimento do colmo; e senescência foliar.

O comprimento da folha emergente foi medido do seu ápice até à lígula da última folha expandida, enquanto a folha expandida teve seu comprimento medido da lígula até seu ápice. O comprimento do colmo foi medido do nível do solo até à lígula da última folha expandida. A senescência foliar foi medida a partir do momento que se iniciou a necrose do tecido, considerando senescente quando no mínimo $50 \%$ da folha apresentavam-se necrosadas (VAN SOEST, 1994).

De posse dessas informações, foram estimadas as seguintes variáveis:

- Taxa de Alongamento da Folha (TAlF): Somatório de todo alongamento da lâmina foliar por perfilho dividido pelo número de dias do período de avaliação - cm/perfilho/dia.

- Taxa de Aparecimento da Folha (TApF): Número de folhas surgidas por perfilho dividido pelo número de dias do período de avaliação folhas/perfilho/dia.

- Duração de Vida da Folha (DVF): Período de tempo entre o aparecimento de uma folha até sua morte - dias.

- Taxa de Alongamento do Colmo (TAlC): Somatório do alongamento do colmo de cada perfilho, dividido pelo número de dias do período avaliado - cm/perfilho/dia.

- Taxa de Senescência Foliar (TSeF): Determinada a partir das medições das folhas que nasceram e não se mantiveram vivas nos perfilhos marcados. Perda de tecido foliar, expressa em - cm/ perfilho/dia.

- Comprimento Final da Folha (CFF): Comprimento médio de todas as folhas expandidas presentes no perfilho, medido do ápice foliar até a lígula - cm.

- Largura da Folha Expandida (LFE): Para determinação da largura da folha expandida, foram 
tomadas medidas da parte mediana da folha $-\mathrm{cm}$.

- Número de Folhas Expandidas por Perfilho (NFExp/Perf): Número médio das folhas completamente expandidas presentes no perfilho.

- Número de Folhas Vivas (NFV): Número médio de folhas em expansão e expandidas por perfilho, desconsiderando as folhas senescentes.

- Número Total de Folhas por Perfilho (NTF/ Perf): Número médio de todas as folhas presentes no perfilho.

- Número de perfilhos por vaso (NP/vaso.): Determinado a partir da marcação dos perfilhos basais, e posteriormente, a contagem dos mesmos.

A produção de massa seca e suas frações foram determinadas através do corte das plantas no final do período experimental. Após o corte, a forragem colhida, pesada e separada em duas partes. A primeira parte foi encaminhada para secagem. A segunda parte da planta foi fracionada e classificadas em folhas vivas, colmo e material senescente. Em seguida foram secas em estufa de circulação forçada de ar a $65^{\circ} \mathrm{C}$ durante 72 horas, segundo metodologia descrita por Silva e Queiroz (2002).

Para a realização da análise química, as plantas foram moídas em moinho tipo Wiley com peneira de malha $1,0 \mathrm{~mm}$, em seguida foram retiradas amostras de 5,0 gramas de cada vaso, as quais foram colocadas em sacos de TNT previamente pesados e secos em estufa a $105^{\circ} \mathrm{C}$. Após esse procedimento os sacos com as amostras, já pesadas, foram encaminhados ao laboratório da EMBRAPA Semiárido onde foram feitas as análises químicas.

A metodologia utilizada para determinação de proteína bruta $(\mathrm{PB})$, fibra insolúvel em detergente neutro (FDN) e fibra insolúvel em detergente ácido (FDA), foi a metodologia descrita por Silva e Queiroz (2002).

Os dados experimentais foram analisados através do pacote estatístico SAS 9.0. As análises de variância foram realizadas utilizando-se o PROC GLM. As médias dos tratamentos foram comparadas pelo teste de Duncan ao nível de 5\% de probabilidade.

\section{Resultados e Discussão}

Os valores da Taxa de Alongamento Foliar (TAlF) diferiram $(\mathrm{P}<0,05)$ sendo que o acesso Biloela resultou em maior TAlF em relação aos demais o que denota um melhor aparato fotossintético, maior eficiência de uso da radiação fotossinteticamente ativa, consequentemente, melhor conversão da energia luminosa em massa de forragem, quando os fatores ambientais não forem limitantes (Tabela 1). A TAlF é uma variável que apresenta alta correlação com o rendimento forrageiro, em função disso, ela tem sido usada como índice de avaliação de genótipos e acessos em trabalhos de seleção (ALEXANDRINO; CANDIDO; GOMIDE, 2011).

Não houve diferenças entre os acessos $(\mathrm{P}>0,05)$ nos valores da Taxa de Aparecimento Foliar (TApF) os quais apresentaram valor médio de 0,25 folha/dia (Tabela 1). Edvan et al. (2011) trabalhando com capim-buffel, cultivar Molopo, encontraram valores de TApF correspondentes a 0,24 folha/dia, resultado próximo ao encontrado neste experimento.

Os acessos Irã, Buchuma e Pusa Giant apresentaram os maiores valores de Taxa de Alongamento de Colmo (TAlC) e resultaram em resposta inversa em relação a TAlF (Tabela 1). Entretanto, esperava-se que estas variáveis fossem diretamente proporcionais uma vez que maior alongamento de colmo gera maior cartucho o que aumenta o percurso da folha dentro do colmo até a completa expansão, consequentemente, resultaria em maior alongamento foliar. 
Tabela 1. Taxa de Alongamento Foliar (TAlF), Taxa de Aparecimento Foliar (TApF), Taxa de Alongamento do Colmo (TAlC), Duração de Vida da Folha (DVF) e Taxa de Senescência Foliar (TSeF) dos acessos de capim-buffel.

\begin{tabular}{cccccc}
\hline Acessos & $\begin{array}{c}\text { TAlF } \\
(\mathrm{cm} / \text { dia })\end{array}$ & $\begin{array}{c}\text { TApF } \\
(\text { Folha/dia })\end{array}$ & $\begin{array}{c}\text { TAlC } \\
(\mathrm{cm} / \text { dia })\end{array}$ & $\begin{array}{c}\text { DVF } \\
(\text { dia })\end{array}$ & $\begin{array}{c}\text { TSeF } \\
(\mathrm{cm} / \text { dia })\end{array}$ \\
\hline Biloela & $8,96 \mathrm{a}$ & 0,26 & $2,72 \mathrm{~b}$ & 17,72 & $1,27 \mathrm{a}$ \\
Tanzânia & $7,78 \mathrm{~b}$ & 0,26 & $2,34 \mathrm{~b}$ & 17,17 & $1,01 \mathrm{bc}$ \\
Pusa Giant & $7,77 \mathrm{~b}$ & 0,27 & $3,03 \mathrm{ab}$ & 18,53 & $0,91 \mathrm{c}$ \\
Buchuma & $7,62 \mathrm{~b}$ & 0,24 & $3,12 \mathrm{ab}$ & 17,45 & $0,87 \mathrm{c}$ \\
Áridus & $6,92 \mathrm{~b}$ & 0,24 & $2,31 \mathrm{~b}$ & 18,17 & $0,91 \mathrm{c}$ \\
Irã & $6,88 \mathrm{~b}$ & 0,24 & $3,62 \mathrm{a}$ & 16,15 & $1,11 \mathrm{ab}$ \\
CV $(\%)$ & 10,85 & 8,15 & 21,32 & 9,31 & 13,64 \\
\hline
\end{tabular}

As médias seguidas pela mesma letra na coluna, não diferem entre si pelo teste de Duncan, ao nível de 5\% de probabilidade $(\mathrm{P}<0,05)$.

Fonte: Elaboração dos autores.

Ao analisar os valores da Duração de Vida da Folha (DVF), observa-se que não houve efeito significativo $(\mathrm{P}>0,05)$ entre os acessos (Tabela 1$)$. A determinação dessa variável para cada espécie é de grande importância tendo em vista que é fundamental na definição da frequência e intensidade de pastejo, evitando perdas de folhas por senescência e morte.

O valor de DVF do capim-buffel deste estudo foi de 17,53 dias, diferente daquele encontrado por Silva et al. (2009) trabalhando com a Brachiaria brizantha de 45,1 dias. Essa diferença está relacionada à fisiologia diferenciada de cada espécie forrageira, que deve ser considerada no estabelecimento do intervalo de cortes. Daí a importância da análise morfogênica para cada espécie nos diferentes sistemas como forma de se estabelecer o manejo correto e com isso intensificar o uso das mesmas.

Os valores da Taxa de Senescência Foliar (TSeF) diferiram $(\mathrm{P}<0,05)$ entre os acessos, ao passo que os acessos Biloela e Irã apresentaram maiores valores, superando os acessos Pusa Giant, Buchuma e Áridus (Tabela 1). A taxa de senescência é uma variável de grande importância, pois demonstra o quanto de material foliar é perdido conforme o manejo adotado (ALEXANDRINO et al., 2004; MATTOS; GOMIDE; HUAMAN, 2005).

Os dados referentes ao Comprimento Final de Folha $(\mathrm{CFF})$ foram distintos $(\mathrm{P}<0,05)$ entre os acessos avaliados (Tabela 2), sendo que o acesso Biloela apresentou a maior média devido a maior TAlF onde gerou folhas mais compridas (Tabela 1). Esta relação também foi observada no acesso Irã, porém o mesmo resultou em menores valores. De acordo com Lemaire e Chapman (1996), os fatores determinantes do comprimento final da folha são variáveis TAlF e TApF, sendo que a TAlF está diretamente correlacionada com o tamanho final da folha.

Também foi constatado efeito $(\mathrm{P}<0,05)$ para os valores de Largura da Folha Expandida (LFE), onde o Biloela apresentou valores maiores, com média de $0,83 \mathrm{~cm}$ (Tabela 2). O comprimento e a largura das folhas são fatores decisivos no estabelecimento da área foliar, possibilitando uma maior interceptação de luz, consequentemente, a obtenção de maiores taxas fotossintéticas. De acordo com Andrade et al. (2005), dentre as variáveis relacionadas ao crescimento e produção das plantas a área foliar destaca-se, visto que $90 \%$ do peso de matéria seca das plantas são devidos à assimilação fotossintética de carbono. Diversos trabalhos têm sido conduzidos evidenciando a importância da manutenção de um IAF residual para a melhoria da produtividade de gramíneas a pasto de espécies de reconhecido valor forrageiro como Panicum maximum (CUTRIM 
JÚNIOR et al., 2010; COSTA E SILVA, 2011; brizantha (GALZERANO et al., 2013a, 2013b); ALARI, 2012; LIMA SANTOS, 2012); Brachiaria Cynodon dactylon (SILVA et al., 2013).

Tabela 2. Comprimento Final da Folha (CFF), Largura de Folha Expandida (LFE), Número de Folhas Expandidas por Perfilho (NFExp/Perf), Número de Folhas Vivas (NFV/perfilho), Número Total de Folhas por Perfilho (NTF/Perf) e Número de Perfilhos por Vaso (NP/Vaso) nos acessos de capim-buffel.

\begin{tabular}{cllccrl}
\hline Acessos & $\begin{array}{l}\text { CFF } \\
(\mathrm{cm})\end{array}$ & $\begin{array}{l}\text { LFE } \\
(\mathrm{cm})\end{array}$ & NFExp/Perf & NFV/Perf & NTF/Perf & NP/Vaso \\
\hline Biloela & $37,82 \mathrm{a}$ & $0,83 \mathrm{a}$ & 5,45 & $7,62 \mathrm{a}$ & 10,85 & $24,0 \mathrm{~b}$ \\
Tanzânia & $30,53 \mathrm{~b}$ & $0,72 \mathrm{~b}$ & 5,30 & $7,75 \mathrm{a}$ & 10,92 & $29,4 \mathrm{ab}$ \\
Pusa Giant & $31,08 \mathrm{~b}$ & $0,68 \mathrm{bc}$ & 4,98 & $7,36 \mathrm{ab}$ & 11,34 & $31,4 \mathrm{a}$ \\
Buchuma & $31,73 \mathrm{~b}$ & $0,67 \mathrm{bc}$ & 4,34 & $6,71 \mathrm{bc}$ & 10,54 & $27,2 \mathrm{ab}$ \\
Áridus & $28,21 \mathrm{bc}$ & $0,70 \mathrm{bc}$ & 4,94 & $7,23 \mathrm{ab}$ & 10,43 & $25,6 \mathrm{~b}$ \\
Irã & $24,85 \mathrm{c}$ & $0,63 \mathrm{c}$ & 4,79 & $6,21 \mathrm{c}$ & 10,47 & $23,8 \mathrm{~b}$ \\
CV (\%) & 12,65 & 9,15 & 11,86 & 8,51 & 9,30 & 15,09 \\
\hline
\end{tabular}

As médias seguidas pela mesma letra na coluna, não diferem entre si pelo teste de Duncan, ao nível de 5\% de probabilidade $(\mathrm{P}<0,05)$.

Fonte: Elaboração dos autores.

Os valores do Número de Folhas Expandidas por Perfilho (NFExp/perf) e Número Total de Folhas por Perfilho (NTF/perf) não diferiram $(\mathrm{P}>0,05)$ entre os acessos, apresentando um número médio de aproximadamente 5,0 e 11,0 folhas por perfilho, respectivamente (Tabela 2). Segundo Gomide e Gomide (2000), o número de folhas por perfilho é razoavelmente constante para um mesmo capim, sendo dependente das condições do meio ambiente e do manejo.

Os acessos Biloela e Tanzânia resultaram em maior Número de Folhas Vivas por Perfilho (NFV/ perf) ao passo que o acesso Irão apresentou o menor valor $(\mathrm{P}<0,05)$ (Tabela 2). O maior NFV/perf remete a maior disponibilidade de folhas para o animal em pastejo e ainda, folhas nutricionalmente com mais valos nutricional. Observou-se que este diferencial foi resultado do maior número de folhas emergentes presentes nestes acessos o que é ratificado pelos valores semelhantes em relação ao NFExp/perf e ao $\mathrm{NTF} /$ perf.

Para o fator perfilhamento, o acesso Pusa Giant destacou-se para esta característica diferindo
$(\mathrm{P}<0,05)$ do Biloela, Áridus e Irã (Tabela 2). Oliveira (2005) avaliando o potencial de cinco variedades de capim-buffel no sertão pernambucano, encontraram resultados para cobertura aérea dos piquetes em que o acesso Pusa Giant se destacou apresentando a maior porcentagem de cobertura do solo, o que ratifica a superioridade deste acesso quanto ao estabelecimento na área.

Os valores da produção de massa seca de lâmina foliar (MSLF) foram similares, com exceção dos acessos Irã e Tanzânia os quais resultaram menor e maior produção de MSLF, respectivamente $(\mathrm{P}<0,05)$ (Tabela 3). A menor produção de folhas do acesso Irã está relacionada com a característica morfológica deste acesso uma vez que prioriza o desenvolvimento de colmo, fato confirmado através da maior TAlC, menor TAlF e maior TSeF (Tabela 1). Ademais, tais características refletiram na baixa relação F/C, menor CFF e baixo NP/Vaso (Tabela 2), ou seja, esse acesso perfilha menos, porém produz perfilhos mais pesados com a presença de colmos mais alongados, o que favorece a produção de colmo em relação à produção de folhas. 
Tabela 3. Produção de massa seca de lâmina foliar (MSLF), colmo (MSC), massa seca do material senescente (MSMS), massa seca total (MST) e relação folha/colmo (F/C) nos acessos de capim-buffel.

\begin{tabular}{cccccc}
\hline Acessos & MSLF & MSC & MSMS & MST & F/C \\
\hline & --------------------- & \\
Biloela & $7,17 \mathrm{ab}^{1}$ & 12,30 & $2,07 \mathrm{~b}$ & 21,51 & $0,58 \mathrm{a}$ \\
Tanzânia & $8,94 \mathrm{a}$ & 14,28 & $2,04 \mathrm{~b}$ & 25,26 & $0,63 \mathrm{a}$ \\
Pusa Giant & $7,8 \mathrm{ab}$ & 13,26 & $1,74 \mathrm{~b}$ & 22,80 & $0,59 \mathrm{a}$ \\
Buchuma & $8,55 \mathrm{ab}$ & 13,98 & $3,18 \mathrm{a}$ & 25,74 & $0,61 \mathrm{a}$ \\
Áridus & $7,47 \mathrm{ab}$ & 11,34 & $1,86 \mathrm{~b}$ & 20,7 & $0,66 \mathrm{a}$ \\
Irã & $6,06 \mathrm{~b}$ & 13,44 & $2,88 \mathrm{a}$ & 22,41 & $0,45 \mathrm{~b}$ \\
CV (\%) & 22,41 & 19,11 & 25,70 & 18,86 & 11,57 \\
\hline
\end{tabular}

As médias seguidas pela mesma letra na coluna, não diferem estatisticamente entre si pelo teste de Duncan, ao nível de $5 \%$ de probabilidade $(\mathrm{P}<0,05)$.

Fonte: Elaboração dos autores.

Não houve diferença significativa $(\mathrm{P}>0,05)$ na produção de massa seca de colmo (MSC) (Tabela 3). Embora tenham sido observada diferenças nas TAlC, TAlF (Tabela 1); CFF e NP (Tabela 2), a produtividade desses acessos é muito similar, sendo que, as diferenças apresentadas entre os acessos estão relacionadas à morfologia, que por sua vez é bastante compensatória.

O mecanismo compensatório de crescimento da planta foi observado no trabalho clássico de Zarrough e Nelson (1980) os quais observaram a relação inversa entre o número de perfilhos e o peso dos perfilhos e estes estão associados ao peso final da planta.

Os maiores valores de massa seca de material senescente (MSMS) foram observados nos acessos Buchuma e Irã, os quais diferiram $(\mathrm{P}<0,05)$ dos demais (Tabela 3). Em valores absolutos estas perdas aparentam ser pequenas, mas em termos de porcentagem pode-se observar a magnitude da perda de massa por senescência uma vez que os acessos Buchuma e Irã chegaram a apresentar, em média, perdas de $30 \%$ de massa seca foliar e $12 \%$ da massa seca total produzida; além disso, as perdas destes acessos forma $10 \%$ superiores em comparação com os acessos Pusa Giant e Áridus.

Não foram observadas diferenças nos valores da relação folha/colmo (F/C) entre os acessos, com exceção do acesso Irã, o qual apresentou a menor relação $\mathrm{F} / \mathrm{C}(\mathrm{P}<0,05)$, correspondente a 0,45 (Tabela 3). Cândido et al. (2005), comenta que a relação folha/colmo é uma importante variável morfogênica que indiretamente diz algo sobre a estrutura do dossel forrageiro.

Segundo Van Soest (1994) e Rodrigues et al. (2008), quanto maior a relação folha/colmo, melhor o valor nutritivo da forragem, pois as folhas são a fração da planta forrageira com maior digestibilidade, por serem mais ricas em proteína bruta e com menor teor de fibra, e influencia o aumento no consumo animal.

Não foram observadas diferenças entre os acessos quanto aos teores de proteína bruta (PB), fibra em detergente neutro (FDN) e fibra em detergente ácido (FDA) analisados nas folhas da planta $(\mathrm{P}>0,05)$ (Tabela 4). 
Tabela 4. Teores de proteína bruta (PB), fibra em detergente neutro (FDN) e fibra em detergente ácido (FDA) em diferentes frações das plantas.

\begin{tabular}{lcccccc}
\hline \multirow{2}{*}{ Acessos } & \multicolumn{2}{c}{ PB (\%) } & \multicolumn{2}{c}{ FDN (\%) } & \multicolumn{2}{c}{ FDA (\%) } \\
\cline { 2 - 6 } & Folha & Parte aérea & Folha & Parte aérea & Folha & Parte aérea \\
\hline Biloela & 10,94 & 7,15 & 75,28 & $74,69 \mathrm{~b}$ & 45,74 & $47,35 \mathrm{ab}$ \\
Tanzânia & 10,47 & 7,86 & 76,40 & $75,02 \mathrm{~b}$ & 43,34 & $44,96 \mathrm{~b}$ \\
Pusa Giant & 11,11 & 7,70 & 75,40 & $77,21 \mathrm{a}$ & 44,13 & $47,69 \mathrm{a}$ \\
Buchuma & 10,21 & 7,53 & 76,65 & $75,45 \mathrm{~b}$ & 43,80 & $44,95 \mathrm{~b}$ \\
Áridus & 10,24 & 7,55 & 76,24 & $74,83 \mathrm{~b}$ & 46,03 & $46,29 \mathrm{ab}$ \\
Irã & 10,61 & 6,93 & 75,35 & $76,17 \mathrm{ab}$ & 46,08 & $46,30 \mathrm{ab}$ \\
CV (\%) & 7,16 & 12,20 & 1,86 & 1,67 & 4,33 & 3,65 \\
\hline
\end{tabular}

As médias seguidas pelo menos uma mesma letra na coluna não diferem estatisticamente entre si pelo teste de Duncan, ao nível de $5 \%$ de probabilidade.

Fonte: Elaboração dos autores.

Em relação à parte aérea, os acessos mostraramse similares $(\mathrm{P}>0,05)$ quanto aos valores do teor de PB. Entretanto os teores de FDN variaram entre 74,69 e 76,17\% nos diferentes acessos e maiores no acesso Pusa Giant $(77,21 \%)(\mathrm{P}<0,05)$ (Tabela 4). De acordo com Van Soest (1994), valores superiores à faixa de $55 \%$ a $60 \%$ de FDN na matéria seca limitam o consumo de forragem. Em contrapartida, Aguiar (1999) afirmou que as forrageiras tropicais possuem altos teores de FDN, geralmente acima de $65 \%$, chegando até $80 \%$. Os valores médios encontrados neste trabalho foram acima dos estabelecidos por Van Soest (1994), porém estão de acordo com Aguiar (1999). Em adição, estes resultados corroboram com Santos et al. (2005) os quais encontraram valores de 74,23\%, trabalhando com pasto diferido de capim-buffel, resultados próximos aos encontrados neste trabalho.

Os teores de FDA da parte aérea apresentaram média de $46 \%$ e foram maiores no acesso Pusa Giant $(\mathrm{P}<0,05)$ (Tabela 4). De acordo com Van Soest (1994), forragens com valores próximos ou abaixo de $30 \%$ de FDA terão alto consumo, enquanto teores acima de $40 \%$ o consumo poderá ser comprometido.

Embora sejam altos os percentuais encontrados neste trabalho os mesmos estão dentro do padrão para a espécie. Em um experimento realizado no
México com cinco genótipos de capim-buffel, García-Dessommes et al. (2007) encontraram teores médios de FDA de 48,2\%.

\section{Conclusão}

Os acessos de capim-buffel testados pouco diferem com relação produção de massa seca, demonstrando que todos são forrageiras promissoras para exploração no semiárido nordestino.

A frequência de corte para todos os acessos de capim-buffel deve ser de aproximadamente 20 dias.

\section{Referências}

AGUIAR, A. P. A. Possibilidades de intensificação do uso da pastagem através de rotação sem ou com uso mínimo de fertilizantes. In: SIMPÓSIO SOBRE MANEJO DE PASTAGEM: FUNDAMENTOS DO PASTEJO ROTACIONADO, 14., 1999, Piracicaba. Anais... Piracicaba: FEALQ, 1999. p. 85-138.

ALARI, F. O. Morfogênese, estrutura e dinâmica do perfilhamento do capim-tanzânia manejado com diferentes indices de área foliar residual, mantido sob lotação intermitente por caprinos da raça Anglo Nubiana. 2012. Dissertação (Mestrado em Zootecnia) - Faculdade de Ciências Agrárias e Veterinárias. Universidade Estadual Paulista Júlio de Mesquita Filho, Jaboticabal.

ALEXANDRINO, E.; NASCIMENTO JÚNIOR, D.; MOSQUIM, P. R.; REGAZZI, A. J.; ROCHA, F. C. 
Características morfogênicas e estruturais na rebrotação da Brachiaria brizantha cv. Marandu submetida a três doses de nitrogênio. Revista Brasileira de Zootecnia, Viçosa, MG, v. 33, n. 6, p. 1372-1379, 2004.

ALEXANDRINO, E.; CANDIDO, M. J. D.; GOMIDE, J. A. Fluxo de biomassa e taxa de acúmulo de forragem em capim Mombaça mantido sob diferentes alturas. Revista Brasileira de Saúde e Produção Animal, Salvador, v. 12, n. 1, p. 59-71, 2011.

ANDRADE, A. C.; FONSECA, D. M.; LOPES, R. S.; NASCIMENTO JÚNIOR, D.; CECON, P. R.; QUEIROZ, D. S.; PEREIRA, D. H.; REIS, S. T. Analise de crescimento do capim-elefante "Napier" adubado e irrigado. Ciência Agrotécnica, Lavras, v. 29, n. 2, p. 415423, mar./abr. 2005.

CÂNDIDO, M. J. D.; GOMIDE, C. A. M.; ALEXANDRINO, E.; GOMIDE, J. A.; PEREIRA, W. E. Morfofisiologia do dossel de Panicum maximum cv. Mombaça sob lotação intermitente com três períodos de descanso. Revista Brasileira de Zootecnia, Viçosa, MG, v. 34, n. 2, p. 406-415, 2005.

CECATO, U.; SKROBOT, V. D.; FAKIR, G. M.; JOBIM, C. C.; BRANCO, A. F.; GALBEIRO, S.; JANEIRO, V. Características morfogênicas do capim-mombaça (Panicum maximum jacq. cv. mombaça) adubado com fontes de fósforo, sob pastejo. Revista Brasileira de Zootecnia, Viçosa, MG, v. 36, n. 6, p. 1699-1706, 2007.

COSTA E SILVA, V. Morfogênese, estrutura e dinâmica de perfilhamento de capim-tanzânia manejado com diferentes IAF residual, sob pastejo de cabras Anglonubiano. 2011. Dissertação (Mestrado em Zootecnia) - Faculdade de Ciências Agrárias e Veterinárias, Universidade Estadual Paulista Júlio de Mesquita Filho, Jaboticabal.

CUTRIM JUNIOR, J. A. A.; CANDIDO, M. J. D.; VALENTE, B. S. M.; CARNEIRO, M. S. de S.; CARNEIRO, H. A. V. C.; CIDRAO, P. M. L. Fluxo de biomassa em capim-tanzânia sob três freqüências de desfolhação e dois resíduos pós-pastejo. Revista Brasileira de Saúde e Produção Animal, Salvador, v. 11, n. 3, p. 618-619, 2010.

SILVA, S. C. da; NASCIMENTO JUNIOR, D. Avanços na pesquisa com plantas forrageiras tropicais em pastagens: características morfofisiológicas e manejo do pastejo. Revista Brasileira de Zootecnia, Viçosa, MG, v. 36, p. 121-138, 2007. Suplemento Especial.

EDVAN, R. L.; SANTOS, E. M.; da SILVA, D. S.; de ANDRADE, A. P.; COSTA, R. G.; VASCONCELOS, W. A. Características de produção do capim-buffel submetido a intensidades e frequências de corte.
Archivos de Zootecnia, Córdoba, v. 60, n. 232, p. 12811289, 2011.

EMPRESA BRASILEIRA DE PESQUISA AGROPECUÁRIA - EMBRAPA. Sistema Brasileiro de Classificação de Solos. Seminário Nacional de Levantamento e Conservação de Solos. 2. ed. Brasília: EMBRAPA, 2006. 306 p.

GALZERANO, L.; MALHEIROS, E. B.; RAPOSO, E.; MORGADO, E. S.; RUGGIERI, A. C. Acúmulo e desaparecimento de forragem e variações na estrutura de pastos de capim-xaraés submetidos a intensidades de pastejo em lotação intermitente. Semina: Ciências Agrárias, Londrina, v. 34, n. 5, p. 1859-1870, 2013b.

Características morfogênicas and estruturas do capim-xaraes submetido a intensidade de pastejo. Semina: Ciências Agrárias, Londrina, v. 34, n. 4, p. 1879-1890, 2013a.

GARCÍA-DESSOMMES， G. J.; LOZANO, R. G. R.; RODRIGUEZ, R. M.; DÍAZ, G. G. R. Ruminal digestion and chemical composition of new genotypes of buffelgrasss (Cenchrus ciliaris L.) under irrigation and fertilization. Interciência, Caracas, v. 32, n. 5, p. 349$353,2007$.

GOMIDE, C. A. M.; GOMIDE, J. A. Morfogênese de cultivares de Panicum maximum Jacq. Revista Brasileira de Zootecnia, Viçosa, MG, v. 29, n. 2, p. 341-348, 2000.

LEMAIRE, G.; CHAPMAN, D. Tissue flows in grazed plant communities. In: HODGSON, J.; ILLIUS, A. W. (Ed.). The ecology and management of grazing systems. Wallingford: Cab International, 1996. p. 3-36.

LIMA SANTOS, N. Estrutura do pasto e comportamento ingestivo de caprinos em capim-tanzânia submetidos a indices de área foliar residual em lotação intermitente. 2012. Tese (Doutorado em Zootecnia) - Faculdade de Ciências Agrárias e Veterinárias, Universidade Estadual Paulista Júlio de Mesquita Filho, Jaboticabal.

MATTOS, J. L. S.; GOMIDE, J. A.; HUAMAN, C. A. M. Crescimento de espécies de Brachiaria sob déficit hídrico e alagamento a campo. Revista Brasileira de Zootecnia, Viçosa, MG, v. 34, n. 3, p. 755-764, 2005.

MOREIRA, J. N.; LIRA, M. A.; SANTOS, M. V. F.; ARAÚJO, G. G. L.; SILVA, G. C. Potencial de produção de capim-buffel na época seca no semiárido Pernambucano. Revista Caatinga, Mossoró, v. 20, n. 3, p. 22-29, 2007.

OLIVEIRA, M. C. Capim Buffel (Cenchrus ciliares L.) desempenho da variedade Pusa Giant, no semiárido de Pernambuco, PE. Petrolina: EMBRAPA-SEMI ÁRIDO, 2005. 24 p. (Boletim, 68). 
RANGEL, A. H. N.; LIMA JÚNIOR, D. M.; BRAGA, A. P.; SIMPLÍCIO, A. A.; AGUIAR, E. M. Suprimento e demanda de nutrientes em sistemas em não equilíbrio. Revista Verde, Mossoró, v. 4, n. 1, p. 14-30, 2009.

RODRIGUES, R. C.; MOURAO, G. B.; BRENNECKE, K.; LUZ, P. H. C.; HERLING, V. R. Produção de massa seca, relação folha/colmo e alguns índices de crescimento do Brachiaria brizantha cv. Xaraés cultivado com a combinação de doses de nitrogênio e potássio. Revista Brasileira de Zootecnia, Viçosa, MG, v. 37, n. 3, p. 394400, 2008.

SANTOS, G. R. A.; GUIM, A.; SANTOS, M. V. F.; FERREIRA, M. A.; LIRA, M. A.; DUBEUX JUNIOR, J. C. B.; SILVA, M. J. Caracterização do pasto de capimbuffel diferido e da dieta de bovinos, durante o período seco no sertão de Pernambuco. Revista Brasileira de Zootecnia, Viçosa, MG, v. 34, n. 2, p. 454-463, 2005.
SILVA, C. C. F.; BONOMO, P.; PIRES, A. J. V.; MARANHÃO, C. M. A.; PATÊS, N. M. S.; SANTOS, L. C. Características morfogênicas e estruturais de duas espécies de braquiária adubadas com diferentes doses de nitrogênio. Revista Brasileira de Zootecnia, Viçosa, MG, v. 38, n. 4, p. 657-661, 2009.

SILVA, D. J.; QUEIROZ, A. C. Análises de alimentos: métodos químicos e biológicos. 3. ed. Viçosa, MG: Universidade Federal de Viçosa, 2002. 165 p.

SILVA, W. L.; GALZERANO, L.; REIS, R. A.; RUGGIERI, A. C. Structural characteristics and forage mass of Tifton 85 pastures managed under three postgrazing residual leaf areas. Revista Brasileira de Zootecnia, Viçosa, MG, v. 42, n. 4, p. 238-245, 2013.

VAN SOEST, P. J. Nutritional ecology of the ruminant. 2. ed. Ithaca: Cornell University Press, 1994. 476 p.

ZARROUGH, K. M.; NELSON, C. J. Regrowth of genotypes of tall fescue differing in yield per tiller. Crop Science, Madison, v. 20, n. 4, p. 540-544, 1980. 